\title{
Prevalence of low back pain and its related factors among pre-hospital emergency personnel in Iran
}

\author{
Ali Imani ${ }^{1}$, Jalal Borna2 ${ }^{2 *}$, Ali Alami ${ }^{3}$, Shahla Khosravan4 ${ }^{4}$, Hadi Hasankhani ${ }^{5}$, Mostafa Bafandeh Zende ${ }^{2}$ \\ ${ }^{1}$ Health Services Management Research Center, Tabriz University of Medical Sciences, Tabriz, Iran \\ 2Emergency Medicine Center, Tabriz University of Medical sciences, Tabriz, Iran \\ ${ }^{3}$ Social Medicine Department, Social Determinants of Health Research Center, School of Medicine, Gonabad University of \\ Medical Sciences, Gonabad, Iran \\ ${ }^{4}$ Community and Mental Health Nursing Department, Social Determinants of Health Research Center, School of Nursing and \\ Midwifery, Gonabad University of Medical Sciences, Gonabad, Iran \\ ${ }^{5}$ Centre of Qualitative Studies, Tabriz University of Medical Sciences, Tabriz, Iran
}

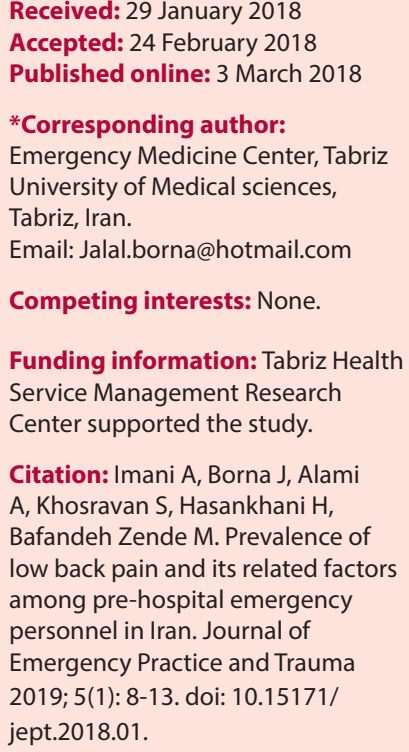

\begin{abstract}
Objective: Low back pain is one of the most important job injuries among emergency medical personnel. This study was carried out to investigate the prevalence of low back pain as well as its physical, mental and managerial predisposing factors among emergency medical personnel in Iran.

Methods: In this analytical cross-sectional study we recruited 298 pre-hospital emergency medical personnel based on census sampling. Data were gathered using Nordic and a research-made questionnaire related to physical, mental and managerial back pain factors. Data were analyzed using SPSS version 20. Descriptive and analytical tests including chisquare test were used appropriately. $P$ value less than 0.05 was considered as the level of significance.

Results: Findings showed that $46.3 \%$ of pre- hospital emergency technicians had a history of low back pain with different intensities. We observed a significant relationship between age, work experience, occupational-physical factors with low back pain $(P>0.001)$. However, there was no significant relationship between occupational-managerial factors and mental-occupational factors with low back pain $(P>0.05)$.

Conclusion: Results show that the prevalence of back pain among emergency medical personnel is high. Identifying the factors associated with back pain can help the managers as well as the personnel to control the problem of back pain and increase employees' productivity.

Keywords: Low back pain, Managerial factors, Mental factors, Nordic questionnaire, Paramedic, Physical factors
\end{abstract}

\section{Introduction}

Low back pain is one of the most prevalent health problems and has a great impact on the quality of adults' lives (1). Back pain is accounted for more than $50 \%$ of musculoskeletal disorders, causing disability in developed countries, health costs and absenteeism (2). Evidence indicates that the direct cost associated with low back pain is the same as cardiovascular diseases but it is more than other diseases, and its indirect cost is more for diseases like cardiovascular disease, rheumatoid arthritis, lung disease, stroke, diabetes and depression (3).

Pre- hospital emergency is one of the important centers in the health care system. Regardless of time and place, it is expected that it performs the therapeutic and transmission task of patients and injured ones (4). Prehospital technicians as the personnel of these units are the people who are often present in accident scenes and perform therapeutic measures. Their working conditions is more difficult compared to other professions $(5,6)$. They encounter many occupational hazards and have more health problems compared to other professions (5). Studies show that one third of them suffer from injury caused by their job at least once in a 6-month period (7). Musculoskeletal injuries, particularly back pain, is one of them and is the reason for early retirement (8). Low back pain is one of the debilitating and costly diseases that pre-hospital emergency personnel become vulnerable to during patient care duties $(8,9)$. It is because they perform 
many duties such as transporting patient and equipment in hard condition alone or double(10). These people are present in ambulances or helicopters for many hours, hence suffering from low back pain caused by vibration too (11). Pre- hospital emergency technicians are often young people who lack sufficient experience and the skills required in lifting the patients and the wounded people. Therefore, this exacerbates the situation and increases the prevalence of low back pain (12). In addition to physical factors, some mental problems have been expressed as the cause of low back pain. Pre-hospital emergency technicians are encountered with a variety of mental stresses such as time limits, scene security, being responsible for the lives of patients, stressful scenes and traumatic stress (13).

The occurrence of low back pain have been investigated in pre-hospital emergency personnel in different countries, for example, among emergency technicians in Japan $76.9 \%$ (5), the United States 48\% (14), Sweden 50\% (10) and in a pilot study conducted in Kashan, Iran which was reported to be $79.17 \%$ (15).

Low back pain has been investigated in many occupations, especially among hospital staff in other countries and Iran; however, studies done at Iranian medical emergency technicians are limited. In general, the probability of low back pain among the personnel is predictable and its related factors have been investigated, Therefore, considering the paucity of studies conducted on low back pain in pre-hospital personnel in Iran as well as lack of evidence in this field in East Azarbaijan province with its special condition (to be situated in a mountainous area), this study aimed to investigate the prevalence and risk factors among emergency medical personnel in this province.

\section{Methods}

This analytical cross-sectional study was carried out in all emergency medical centers of East Azarbaijan in Iran in 2016. Data concerning low back pain were collected using Nordic questionnaire. This questionnaire was developed by Nordic for evaluating Work-related Musculoskeletal Disorders. The validity and reliability of the questionnaire was more than 0.7 in a study conducted by Mokhtarinia et al (17). In addition, a researcher- made questionnaire was used to assess the factors associated with low back pain in three domains namely "physical-occupational ", "mentaloccupational" and "occupational-managerial" factors. This questionnaire has 40 questions with yes and no options. Its validity was confirmed by five experts. In terms of its reliability, we used Cronbach's alpha coefficient and it was reported $87 \%$. Inclusion criteria included: $(a)$ emergency medical personnel with two years of work experience (b) not suffering from low back pain before employment. Exclusion criteria encompassed unemployment in other healthcare sectors, and also a history of any work-related injury or accident during the recruitment period. Our sample size was 322 people. It is important to mention that
24 questionnaires were not returned. The questionnaires were sent to the workplace and were analyzed after data collection. In addition, all participants were males. We used census sampling and participants completed a selfmade questionnaire. Data were analyzed using descriptive and analytical tests including chi-square test. SPSS version 22 was used for data analysis. The level of significance was set at below 0.05. Concerning ethical consideration, the purpose of the study was explained to participants and they had the freedom to leave the study.

\section{Results}

The mean (standard deviation) age was 36.26 (7.34) years, work experience of participants was 10.10 (6.015) years and body mass index was equal to 25.69 (2.91). Table 1 shows other demographic characteristics of the participants.

Based on the results, $46.3 \%$ of emergency medical personnel suffered from low back pain due to various reasons.

$24.1 \%$ of technicians suffered from muscle spasms; $13.1 \%$ of them had intervertebral disc; $0.7 \%$ had osteoarthritis; $1 \%$ suffered from anatomical disorder; $0.7 \%$ had other reasons; $7.7 \%$ did not know the relevant factors of their back pain; and $52.7 \%$ had no low back pain. There was a significant relationship between age and increased work experience with low back pain $(P<0.001)$.

In terms of intensity of discomfort, $7.7 \%$ had persistent pain, $29.9 \%$ had occasional pain, $9.9 \%$ seldom had the pain and $7 \%$ were without low back pain. $5.1 \%$ of patients had surgery and the rest were treated by taking medicine or without it.

According to the participants, $36.2 \%$ of low back pain was related to working in the emergency department, $10.7 \%$ was due to other cases including sports and events irrelevant to their jobs. $19.1 \%$ of the units under study were damaged over the past 6 months.

The frequency distribution of physical-occupational factors associated with low back pain is shown in Table 2. According to these data, there was a significant relationship between low back pain and being on duty and injuring the back, doing the task on the injured people on the ground, performing CPR, driving, transporting the patient, carrying emergency equipment, being in a standing position while performing emergency measures, going up the stairs to carry the patient, bending and sitting in the rear cabin of ambulance during the operation $(P<0.001)$.

The frequency distribution of mental-occupational factors in the pre-hospital emergency personnel is depicted in Table 3. According to the data, responsibility to save and preserve the lives of patients is the most important source of occupational stress in pre-hospital emergency technicians during their mission. Based on chi-square test, there was no significant relationship between mentaloccupational stress factors and low back pain $(P>0.05)$. 
Table 1. Demographic characteristics of the technicians participating in the study $(\mathrm{N}=298)$

\begin{tabular}{|c|c|c|}
\hline Variable & & No. (\%) \\
\hline \multirow{5}{*}{ Education } & Master's degree & $11(3.7)$ \\
\hline & Bachelor's degree & $106(35.6)$ \\
\hline & Associate degree & $152(51.0)$ \\
\hline & Paramedic & $27(9.1)$ \\
\hline & Without reply & $2(0.6)$ \\
\hline \multirow{3}{*}{ Marital status } & Married & $250(83.9)$ \\
\hline & Single & $47(15.8)$ \\
\hline & Without reply & $1(0.3)$ \\
\hline \multirow{3}{*}{ Workplace } & Urban & 109 (36.6) \\
\hline & Road & $81(27.2)$ \\
\hline & Urban and road & $108(36.2)$ \\
\hline \multirow{5}{*}{ Level of exercising } & Always & $58(19.5)$ \\
\hline & Sometimes & $145(48.7)$ \\
\hline & Rarely & $78(26.2)$ \\
\hline & Never & $11(3.7)$ \\
\hline & Without reply & $6(1.9)$ \\
\hline \multirow{5}{*}{$\begin{array}{l}\text { Level of satisfaction } \\
\text { among medical } \\
\text { emergency } \\
\text { personnel }\end{array}$} & Very satisfied & $30(10.1)$ \\
\hline & Satisfied & $209(70.1)$ \\
\hline & Dissatisfied & $40(13.4)$ \\
\hline & Very dissatisfied & $12(4.0)$ \\
\hline & Without reply & $7(2.3)$ \\
\hline \multirow{5}{*}{$\begin{array}{l}\text { Condition of the beds } \\
\text { used in emergency } \\
\text { centers }\end{array}$} & Good & $31(10.4)$ \\
\hline & Medium & $87(29.2)$ \\
\hline & Weak & $73(24.5)$ \\
\hline & Bad & $99(33.2)$ \\
\hline & Without reply & $8(2.7)$ \\
\hline \multirow{5}{*}{$\begin{array}{l}\text { Condition of chairs } \\
\text { used in emergency } \\
\text { centers }\end{array}$} & Good & $23(7.7)$ \\
\hline & Medium & $99(33.2)$ \\
\hline & Weak & $89(29.9)$ \\
\hline & Bad & $78(26.2)$ \\
\hline & Without reply & $9(3.0)$ \\
\hline \multirow{3}{*}{$\begin{array}{l}\text { Number of } \\
\text { technicians per } \\
\text { mission }\end{array}$} & Two & $223(75.0)$ \\
\hline & Three & $45(15.0)$ \\
\hline & $\begin{array}{l}\text { Depends on the people } \\
\text { present at the scene, or } \\
\text { patients' relatives }\end{array}$ & $30(10.0)$ \\
\hline \multirow{4}{*}{$\begin{array}{l}\text { The number of days } \\
\text { of employment per } \\
\text { month }\end{array}$} & Fewer than 10 days & $28(9.4)$ \\
\hline & 10-15 days & $202(67.8)$ \\
\hline & More than 15 days & $60(20.1)$ \\
\hline & Without reply & $8(2.7)$ \\
\hline
\end{tabular}

The frequency distribution of occupational-managerial stress factors in the pre-hospital emergency personnel participating in this study is shown in Table 4. According to these data, there was no significant relationship between mental-occupational stress factors and low back pain $(P>0.05)$ exept 2 variables of encountring stressful and shocking scences, responsiveness at the scene (Table 3).

\section{Discussion}

This study aimed to investigate the prevalence of low back pain among emergency medical personnel as well as its relative factors in Iran. In this study the prevalence of low back pain was $46.3 \%$ which is consistent with the findings of Crill and Hostler, who determined the prevalence of low back pain in pre-hospital emergency technicians as $47.8 \%$ (10). According to International Association of Emergency Technicians, the prevalence of low back pain is $47 \%$ (18). In this study, the prevalence of intervertebral disk was $13.1 \%$ which is consistent with the study carried out by Aliabadi et al. They estimated the intervertebral disk and low back pain in nurses as $12.1 \%$ and $13 \%$ respectively (19). In another study, the prevalence of intervertebral disk among the emergency technicians was reported $53.8 \%$ (8). In our study, the rate of injury to low back was 19.1 during 6 months. It was reported 30\% and $61 \%$ in another study (20). In this study, continuing to do the mission in spite of injury to low back was the most prevalent factor concerning low back pain which is consistent with the studies carried out on firefighters (21). However, in another study in Iran, it was determined that the most prevalent factor concerning low back pain was lifting the patient (15). In our study, 36.2\% of participants did not suffer from low back pain prior to working in this job which is consistent with a study carried out by Crill and Hostler which reported it to be $40 \%$. In a qualitative study using focus groups and semi-structured questionnaire with 131 participants this amount was $56 \%$ (10). This increase can be due to the accuracy obtained in qualitative studies compared to quantitative studies.

In terms of the relationship between low back pain and experience and age findings showed a significant positive correlation. In this case as age increases, the risk of low back pain increases too $(P<0.001)$. The results of this study are in line with the findings of other studies. In a study, it was found that technicians over 30 years and paramedics suffered from low back pain more than technicians below 30 years and novice technicians (22). An increase in age and work experience is associated with the decline of motor function and physical activity of an individual leading to low back pain (14).

The average body mass index (BMI) in the overweight and the regular exercise is $(25.69 \pm 2.91)$ and $19.5 \%$ respectively indicating that emergency technicians are not in suitable conditions; while flexibility and a suitable BMI are considered important issues concerning the prevention of low back pain. Crill and Hostler indicated that an increased BMI is the cause of low back pain in the emergency personnel (10). In a study conducted on soldiers findings showed that doing aerobic exercises is an important factor in the incidence of back pain in the future (23). In a prospective study on industrial workers, it was shown that suitable physical conditions and the strength of the legs were predictive factors in reducing low back pain (24).

Many studies have shown that there is a relationship between smoking and low back pain (25-27). However, we did not observe a significant relationship between 
Table 2. Frequency distribution of occupational-physical stress factors in pre-hospital emergency personnel and its relationship with low back pain

\begin{tabular}{|c|c|c|c|c|}
\hline Occupational-physical stress factors & $\begin{array}{l}\text { Low back pain } \\
\text { No. (\%) }\end{array}$ & $\begin{array}{l}\text { no Low back pain } \\
\text { No. }(\%)\end{array}$ & Chi-square test & $P$ value \\
\hline Continuing to do the mission in case of injury to low back & $127(42.6)$ & $171(57.4)$ & 180.6 & $<0.001$ \\
\hline Working on the injured patients on the ground & $110(36.9)$ & $188(63.1)$ & 215.2 & $<0.001$ \\
\hline Doing resuscitation & $95(31.9)$ & $203(68.1)$ & 225.6 & $<0.001$ \\
\hline The presence of pain while driving an ambulance & $66(22.1)$ & $232(77.9)$ & 210.6 & $<0.001$ \\
\hline Carrying the patient & $82(27.5)$ & $216(72.5)$ & 225.7 & $<0.001$ \\
\hline Carrying emergency equipment & $82(27.5)$ & $216(72.5)$ & 227 & $<0.001$ \\
\hline Standing while doing emergency measures & $63(21.1)$ & $78(26.2)$ & 217.8 & $<0.001$ \\
\hline Going up the stairs to carry the patient & $57(19.2)$ & $241(80.8)$ & 221.5 & $<0.001$ \\
\hline Bending during operation & $48(16.2)$ & $250(83.8)$ & 221.6 & $<0.001$ \\
\hline Sitting in ambulance cabin & $34(11.4)$ & $264(88.6)$ & 225.4 & $<0.001$ \\
\hline
\end{tabular}

Table 3. Frequency distribution of mental-occupational factors in the pre-hospital emergency personnel and its relationship with low back pain

\begin{tabular}{|c|c|c|c|c|c|}
\hline Mental-occupational stress factors & $\begin{array}{l}\text { Low back pain } \\
\text { N (\%) }\end{array}$ & $\begin{array}{l}\text { No Low back pain } \\
\text { N (\%) }\end{array}$ & $\begin{array}{l}\text { Without reply } \\
\text { N (\%) }\end{array}$ & $\begin{array}{l}\text { Chi-square } \\
\text { test }\end{array}$ & $\begin{array}{l}P \\
\text { value }\end{array}$ \\
\hline Responsibility to save and preserve the lives of patients & $215(72.1)$ & $75(25.2)$ & $8(2.7)$ & 0.95 & 0.622 \\
\hline Encountering stressful and shocking scene & $149(47)$ & $149(50)$ & $9(3)$ & 8.747 & 0.013 \\
\hline Responsiveness at the scene & $137(46)$ & $153(51.3)$ & $8(2.7)$ & 3.428 & 0.018 \\
\hline Considering the security of oneself and the colleague & $135(45.3)$ & $154(51.7)$ & $9(3)$ & 0.062 & 0.969 \\
\hline Time limitation & $129(43.3)$ & $161(54)$ & $8(2.7)$ & 2.767 & 0.251 \\
\hline Protecting the ambulance from the damage incurred & $102(34.2)$ & $187(62.8)$ & $9(3)$ & 3.37 & 0.185 \\
\hline Feeling low back pain in case of stress & $100(33.6)$ & $175(58.7)$ & $23(7.7)$ & 5.666 & 0.129 \\
\hline Stress following the accident & $83(27.9)$ & $206(69.1)$ & $9(3)$ & 1.273 & 0.529 \\
\hline
\end{tabular}

Table 4. Frequency distribution of occupational-managerial stress factors in the pre-hospital emergency personnel and its relationship with low back pain

\begin{tabular}{|c|c|c|c|c|}
\hline Occupational-managerial stress factors & Variable situation & No. (\%) & Chi-square test & P value \\
\hline \multirow{3}{*}{ Training how to lift and carry the patient } & Yes & $242(81.2)$ & \multirow{3}{*}{2.197} & \multirow{3}{*}{0.333} \\
\hline & No & $48(16.1)$ & & \\
\hline & Without reply & $8(2.7)$ & & \\
\hline \multirow{3}{*}{ Availability of suitable equipment for carrying the patient } & Yes & $194(65.1)$ & \multirow{3}{*}{2.884} & \multirow{3}{*}{0.41} \\
\hline & No & $89(29.9)$ & & \\
\hline & Without reply & $15(5)$ & & \\
\hline \multirow{3}{*}{$\begin{array}{l}\text { Training to know the causes of back pain while starting to } \\
\text { work }\end{array}$} & Yes & $154(51.7)$ & \multirow{3}{*}{3.211} & \multirow{3}{*}{0.201} \\
\hline & No & $134(45)$ & & \\
\hline & Without reply & $10(3.3)$ & & \\
\hline \multirow{2}{*}{ Sports facilities of emergency centers } & Has & $11(3.7)$ & \multirow{2}{*}{3.676} & \multirow{2}{*}{0.159} \\
\hline & Does not have & $278(93.3)$ & & \\
\hline
\end{tabular}

smoking and low back pain. This can be related to the concerns associated with smoking because of the nonsmoking rules among the employees and government offices in Iran.

This study showed that emergency personnel have long shift hours. Another study indicated that long shift work and speeding up the work along with physical and emotional demands increased the prevalence of skeletal muscle diseases (28).

Various physical factors cause a pressure on lumbar, providing background for low back pain. In this study, there was a significant relationship between low back pain and occupational-physical factors. It seems that the prevalence of low back pain can be reduced with logical 
presence of technicians in their shift work.

Evidence-based studies show that picking the right equipment, carrying the patient and training the personnel can prevent work-related low back pain $(18,29)$. In our study training the personnel had increased compared to the year before. In addition, $65.1 \%$ of technicians believed that using long backboard, scope, and chair stretcher were more convenient to carry the patient. In a study by Fisher et al conducted on 675 technicians, $23.5 \%$ said that the ambulance equipment was not suitable (18). In this study, $75.5 \%$ of emergency medical technicians carried patients in two which severely caused low back pain. In a study, it was found that even lifting a standard $50 \mathrm{~kg}$ patient without overweight in safe conditions would cause low back pain in health care providers (30). Furthermore, in a study it was indicated that fewer individuals in the prehospital emergency room could affect the quality of the cardiovascular and pulmonary resuscitation of overweight patients (31). In this study, resting beds and chairs were in an unfavorable situation. A study by Arial et al showed that, in addition to training and completeness of the patient's carrying equipment, improving facilities such as beds and chairs are among the appropriate strategies to facilitate better recovery between missions (32).

In our study, emergency personnel were often satisfied with their jobs. A study in Japan also found that emergency technicians were highly satisfied in spite of stress and occupational injuries (5). Therefore, the hypothesis that occupational injuries would reduce job satisfaction is not confirmed and it is necessary to investigate the reasons for job satisfaction. This finding and other physical findings show that physical factors cause back pain more than mental factors (33).

In this study, there was no relationship between low back pain and occupational stress, while another study showed that there was a relationship between occupational stress and low back pain (34). Moreover, in a study by Karahan et al, it was found that the main reason for low back pain was mental stresses (20).

The limitations of this research included self-report and lack of clinical measurement.

\section{Conclusion}

The findings of the present study indicated that low back pain is a common problem among emergency medical personnel. In addition, there are some occupationalphysical factors in this job that lead to injury to low back pain. Once managers are cognizant of these outcomes, they can provide the groundwork for the activities of emergency technicians by taking into account the age, work experience, reducing mental stress, creating sports facilities at emergency sites, encouraging physical training and reducing work time.

\section{Ethical issues}

This study was approved by the ethics committee with code number TBZMED.REC.1394.808.

\section{Acknowledgement}

This project was financially approved by the Research Council of Tabriz Health Service Management Research Center on December 30, 2016, under Project No. $6964 / 77 / 5$. Hereby, researchers are grateful to the respected research community. We are also grateful to the honored colleagues of the medical emergencies of East Azerbaijan province who helped the researchers in conducting this study.

\section{Authors' contributions}

All authors contributed to study concept, design, data gathering and manuscript preparation.

\section{References}

1. Leroux I, Dionne CE, Bourbonnais R. Psychosocial job factors and the one-year evolution of back-related functional limitations. Scand J Work Environ Health 2004; 30(1): 47-55.

2. Beurskens AJ, de Vet HC, Koke AJ, van der Heijden GJ, Knipschild PG. Measuring the functional status of patients with low back pain. Assessment of the quality of four disease-specific questionnaires. Spine (Phila Pa 1976) 1995; 20(9): 1017-28.

3. Maniadakis N, Gray A. The economic burden of back pain in the UK. Pain 2000; 84(1): 95-103.

4. Studnek JR, Crawford JM. Factors associated with back problems among emergency medical technicians. Am J Ind Med 2007; 50(6): 464-9. doi: 10.1002/ajim.20463.

5. Okada N, Ishii N, Nakata M, Nakayama S. Occupational stress among Japanese emergency medical technicians: Hyogo Prefecture. Prehosp Disaster Med 2005; 20(2): 11521.

6. Young KM, Cooper CL. Occupational stress in the ambulance service: a diagnostic study. Journal of Managerial Psychology 1995; 10(3): 29-36. doi: $10.1108 / 02683949510081356$.

7. Sterud T, Ekeberg O, Hem E. Health status in the ambulance services: a systematic review. BMC Health Serv Res 2006; 6: 82. doi: 10.1186/1472-6963-6-82.

8. Vlok J. An investigation into the prevalence and occupational risk factors of low back pain in emergency medical services personnel [dissertation]. KwaZulu Natal, South Africa: Durban University of Technology; 2005.

9. Rodgers LM. A five year study comparing early retirements on medical grounds in ambulance personnel with those in other groups of health service staff: Part II: Causes of retirements. Occup Med 1998; 48(2): 119-32. doi: 10.1093/ occmed/48.2.119.

10. Crill MT, Hostler D. Back strength and flexibility of EMS providers in practicing prehospital providers. J Occup Rehabil 2005; 15(2): 105-11.

11. Palmer KT, Griffin MJ, Bendall H, Pannett B, Coggon D. Prevalence and pattern of occupational exposure to whole body vibration in Great Britain: findings from a national survey. Occup Environ Med 2000; 57(4): 229-36. doi: 10.1136/oem.57.4.229. 
12. Schwartz RJ, Benson L, Jacobs LM. The prevalence of occupational injuries in EMTs in New England. Prehosp Disaster Med 1993; 8(1): 45-50.

13. Maguire BJ, Hunting KL, Guidotti TL, Smith GS. Occupational injuries among emergency medical services personnel. Prehosp Emerg Care 2005; 9(4): 405-11. doi: 10.1080/10903120500255065.

14. Berger W, Coutinho ES, Figueira I, Marques-Portella C, Luz MP, Neylan TC, et al. Rescuers at risk: a systematic review and meta-regression analysis of the worldwide current prevalence and correlates of PTSD in rescue workers. Soc Psychiatry Psychiatr Epidemiol 2012; 47(6): 1001-11. doi: 10.1007/s00127-011-0408-2.

15. Adib-Hajbaghery $M$, Zohrehea J. Back pain among paramedics: a pilot study. Nurs Midwifery Stud 2013; 2(4): 103-4.

16. Deros BM, Daruis DD, Thiruchelvam S, Othman R, Ismail D, Faezah Rabani N, et al. Evaluation on ambulance design and musculoskeletal disorders risk factors among ambulance emergency medical service personnel. Iran J Public Health 2016; 45(1): 52-60.

17. Mokhtarinia H, Shafiee A, Pashmdarfard M. Translation and localization of the Extended Nordic Musculoskeletal Questionnaire and the evaluation of the face validity and test-retest reliability of its Persian version. Journal of Ergonomics 2015; 3(3): 21-9.

18. Fisher TF, Wintermeyer SF. Musculoskeletal disorders in EMS: Creating employee awareness. Prof Saf 2012; 57(7): 30-4.

19. Aliabadi Z, Kafaie S, Sarchahi K, PoorSadegh A, Kazemi M. Prevalence of herniated lumbar disk among nurses working in two educational hospitals of Birjand University of Medical Sciences. Mod Care J 2010; 7(1): 25-9.

20. Karahan A, Kav S, Abbasoglu A, Dogan N. Low back pain: prevalence and associated risk factors among hospital staff. J Adv Nurs 2009; 65(3): 516-24. doi: 10.1111/j.13652648.2008.04905.x.

21. Liao H, Arvey RD, Butler RJ, Nutting SM. Correlates of work injury frequency and duration among firefighters. J Occup Health Psychol 2001; 6(3): 229-42.

22. Maetzel A, Li L. The economic burden of low back pain: a review of studies published between 1996 and 2001. Best Pract Res Clin Rheumatol 2002; 16(1): 23-30. doi: 10.1053/ berh.2001.0204.
23. Feuerstein M, Berkowitz SM, Huang GD. Predictors of occupational low back disability: implications for secondary prevention. J Occup Environ Med 1999; 41(12): 1024-31.

24. Stevenson JM, Weber CL, Smith JT, Dumas GA, Albert WJ. A longitudinal study of the development of low back pain in an industrial population. Spine (Phila Pa 1976) 2001; 26(12): 1370-7.

25. Ernst E. Smoking and back pain. Ann Rheum Dis 1991; 50(9): 658-9. doi: 10.1136/ard.50.9.658-c.

26. Scott SC, Goldberg MS, Mayo NE, Stock SR, Poitras B. The association between cigarette smoking and back pain in adults. Spine (Phila Pa 1976) 1999; 24(11): 1090-8.

27. Shiri R, Karppinen J, Leino-Arjas P, Solovieva S, ViikariJuntura E. The association between smoking and low back pain: a meta-analysis. Am J Med 2010; 123(1): 87.e7-35. doi: 10.1016/j.amjmed.2009.05.028.

28. Lipscomb J, Trinkoff A, Brady B, Geiger-Brown J. Health care system changes and reported musculoskeletal disorders among registered nurses. Am J Public Health 2004; 94(8): 1431-5.

29. Collins JW, Wolf L, Bell J, Evanoff B. An evaluation of a "best practices" musculoskeletal injury prevention program in nursing homes. Inj Prev 2004; 10(4): 206-11. doi: 10.1136/ ip.2004.005595.

30. Marras WS, Davis KG, Kirking BC, Bertsche PK. A comprehensive analysis of low-back disorder risk and spinal loading during the transferring and repositioning of patients using different techniques. Ergonomics 1999; 42(7): 904-26. doi: 10.1080/001401399185207.

31. Reminiac F, Jouan Y, Cazals X, Bodin JF, Dequin PF, Guillon A. Risks associated with obese patient handling in emergency prehospital care. Prehosp Emerg Care 2014; 18(4): 555-7. doi: 10.3109/10903127.2014.912708.

32. Arial M, Benoit D, Wild P. Exploring implicit preventive strategies in prehospital emergency workers: a novel approach for preventing back problems. Appl Ergon 2014; 45(4): 1003-9. doi: 10.1016/j.apergo.2013.12.005.

33. Hoogendoorn WE, van Poppel MN, Bongers PM, Koes BW, Bouter LM. Systematic review of psychosocial factors at work and private life as risk factors for back pain. Spine (Phila Pa 1976) 2000; 25(16): 2114-25.

34. Yip Y. A study of work stress, patient handling activities and the risk of low back pain among nurses in Hong Kong. J Adv Nurs 2001; 36(6): 794-804. 